\title{
Xylitol syrup and xylitol chewing gum were both effective in preventing acute otitis media
}

Uhari $M$, Kontiokari $I$, Niemelä $M$. A novel use of xylitol sugar in preventing acute otitis media. Pediat rics. 1998 Oct; 102:879-84.

\section{Question}

Among healthy children in day care, do xylitol syrup, xylitol chewing gum, or xylitol lozenges prevent acute otitis media (AOM)?

Design

Randomised controlled trial with 3-month follow-up.

\section{Setting}

A department of paediatrics in a university medical centre in Oulu, Finland.

\section{Patients}

857 children ( $54 \%$ boys) were recruited from 34 day-care centres. Children who were receiving antmictobial prophylactics or had a congenital craniofacial malformation or stuctural middle-ear abnormality were excluded. 764 children $(89 \%)$ completed the study.

\section{Intervention}

Children who were too young to chew gum (mean age $2.2 \mathrm{y}$ ) were allocated to xylitol syrup (10 g of xylitol/d) $(n=159)$ or a control syrup $(0.5 \mathrm{~g}$ of xylitol/d) $(n=165)$ at a dosage of $5 \mathrm{~mL}$ given 5 times/d. Children who were old enough to chew gum (mean age 4.6 y) were allocated to xylitol chewing gum $(8.4 \mathrm{~g}$ of xylitol/d) $(n=179)$, control chewing gam $(0.5 \mathrm{~g}$ of xylitol $/ \mathrm{d})(n=178)$, or $x y$ litol lozenges $(10 \mathrm{~g}$ of $x y$ litol $/ \mathrm{d}$ ) $(n=176), 2$ pieces of gum or 3 lozenges were given 5 times/d and chewed for $\geq 5$ minutes

\section{Main outcome measure}

Incidence of AOM defined as tympanometric evidence of middle-ear effusion, otoscopic evidence of tympanic membrane inflammation, and the presence of symptoms of acute respiratory infection.

\section{Main results}

Fewer children who received xylitol syrup had $\geq 1$ episode of AOM than did children who received control syrup $(P=0.028$ ) (Table). Xylitol chewing gum also led to fewer children with $\geq I$ episode of AOM than did control gum $(P=0.025$ ) (Table). Children who re ceived xylitol lozenges had a lower in- cidence of AOM than those chewing control gum, but the difference did not reach statistical significance $(P=0.30)$ (Table). Antimicrobial use was lower in the xylitol syrup group than in the control syrup group $(P=0.012)$ and lower in the xylitol chewing gum group than in the control gum group $(P=0.046)$.

\section{Conclusions}

Xylitol syrap and xylitol chewing gum were effective in reducing the incidence of acute otitis media in children attending day-care centres. Xylitol lozenges were less effective.

Soutres of funding: Gmil Aaltonen Foundation, Maud Kuistila Fondation; Foundation for $p_{p_{-}}$

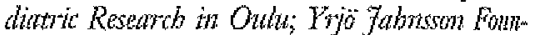
dation. Chewing gum and syzus prouided by Hobtamiaki-Letf, Leiras, and Orion-Fanmos.

For correspondence: Dr: M. Ubati, Depatment of Pediatrics, University of Oulhi, FN 90220 Onlu, Fiviand. $9 A X 358-8-315-5559$

Xylitol syrup vs control syrup and xylitol gum or lozenges vs control gum for incidence of $\geq 1$ episode of acute otitis media at 3 months*

\begin{tabular}{lccc}
\hline Comparison & Event rates & RRR $(95 \%$ CD $)$ & NNT (CI) \\
\hline $\begin{array}{l}\text { Xylitol syrup vs } \\
\text { control syrup }\end{array}$ & $29 \%$ vs $41 \%$ & $30 \%(4.6$ to 55$)$ & $8(4$ to 53$)$ \\
$\begin{array}{l}\text { Xylitol gum vs } \\
\text { control gum }\end{array}$ & $16 \%$ vs $28 \%$ & $40 \%(10$ to 71$)$ & $9(5$ to 36$)$ \\
$\begin{array}{l}\text { Xylitol lozenges vs } \\
\text { control gum }\end{array}$ & $22 \%$ vs $28 \%$ & $20 \%(-13$ to 51$)$ & Not significant \\
\hline
\end{tabular}

"Abbreviations defined in Glossary; NNT and CT calculaced from data in article.

\section{Commentary}

Uhari and colleagues provide solid evidence that xylitol reduces the incidence of AOM in children by about one third, a clinically important effect. However, several problems preclude immediate recommendation for its use.

First, the safety of gum and lozenges for young children is suspect. In this study, gam and lozenges were given to children as young as 18 months. Fard candies and gum are known choking hazards and advising young children to use them regulatly would almost certainly lead to an increase in aspiration $(1,2)$. The absence of aspiration in a study of this size is nevertheless consistent with an actual aspiration rate as high as 6 per 1000 children in 3 months.

Second, among children taking $x y l i t o l$ in any form, the dropout rate was neatly twice that for those receiving placebo $(13 \%$ ws $7 \%$, relative risk $1.8,95 \% \mathrm{CI} 1.2$ to 2.8$)$. This excess may have been caused by chance, but it was confined to the syrup and lozenge groups, suggesting side effects specific to those forms. The side effects of xylitol syrup, the only acceptable dosage form for young children, clearly warrant further study.

Finally, the syrup was administered 5 times daily over several minutes. Long-term com. pliance with this regimen would be difficult.
A study showing safety and efficacy of $x$ lit tol syrup given as a twice-daily bolus would greatly increase the feasibility of using xylitol for prevention of $A O M$ in childres

Michael B. Aldouts, MD, WPH University of Arizona College of Weditw Turson, Artzond, USt

\section{References}

A Rimell FL, Thome A Jr, Stool S, et at Characteristics of objects that cause cholo Characteristics of objects that cat:1763-6.

ing in children. JAVIA 1995;274100n AH Acute forcion body laryngo-tracheal obstron tion: a cause for sudden ard unexpected dest in children. Pediatrics. 1971;48:281-5 